ORLANDI, Eni (Org.). Análise de Discurso: Michel Pêcheux. Campinas, SP: Pontes, 2011. 315p. Resenhado por Eduardo Alves Rodrigues (Doutorando - DL/IEL/Unicamp).

\title{
Retorno a/de Pêcheux: uma tomada de posição frente à discursividade e ao modo de ler o mundo politicamente
}

Eduardo Alves Rodrigues

[...] em geral, "a gente sabe o que diz", falamos na evidência do ideológico [...]

(Michel Pêcheux)[1]

Análise de Discurso: Michel Pêcheux foi lançado no primeiro semestre de 2011 e já se encontra em sua terceira edição (abril, 2012), com quase nenhuma alteração[2]. Começo com esse dado porque constitui, a meu ver, forte indício de que o interesse acadêmico em Michel Pêcheux (França, 1938-1983) mantém-se vivo e vigoroso no Brasil, ou pelo menos em certas instâncias universitárias brasileiras, sobretudo nos campos dos estudos da linguagem e das ciências humanas e sociais.

O livro se apresenta como uma coleção de 18 textos de Michel Pêcheux, dentre os quais um texto de 1966, que Pêcheux assina sob o pseudônimo de Thomas Herbert, e outros quatro textos que publica em co-autoria com antigos companheiros de trabalho: Françoise Gadet, Claudine Haroche, Paul Henry, Jacqueline Léon. A maioria desses textos tem versão brasileira inédita e foram escolhidos e reunidos pela Profa. Eni Orlandi, que organizou um conjunto de pesquisadores habituados à leitura de Pêcheux e experientes no trabalho com a teoria do discurso por ele fundada. Grande parte dos originais - publicados em periódicos, atas de congressos e colóquios, ou sob forma de entrevista ou conferência - já circula no país, de maneira mais ou menos restrita, há bastante tempo e integra, por exemplo, o Fundo Michel Pêcheux[3], disponível desde 2006 para consulta no Centro de Documentação Urbana (CEDU) do Laboratório de Estudos Urbanos (Labeurb), sediado na Universidade Estadual de Campinas (Unicamp).

Vistos em conjunto, os textos perfazem quase duas décadas - 1966-1983, incluindo textos póstumos publicados em 1984, 1990, 1991 - de trabalho de Michel Pêcheux, dando visibilidade a aspectos do processo que sustentou sua tomada de posição - teórica, política, marxista, posição de vida e de resistência e de luta corajosa - frente à discursividade e ao processo de produção de "sua" Teoria do Discurso - a "sua" Análise do Discurso. Por meio desse conjunto de textos que forja a unidade do volume organizado pela Profa. Eni Orlandi, produzse mais de uma vez e em certa medida acesso ao movimento de fundação e estabelecimento da Análise de Discurso "de" Michel Pêcheux. Movimento de trabalho de um grande autor do século XX que se debruçou, refletiu sobre, discutiu e analisou a questão da significação, da constituição do sentido, da relação entre linguagem, sujeito, história e o político, o simbólico, a contradição, a ideologia que a constituem. 
Com efeito, a publicação desses textos assim reunidos em versão brasileira produz outra via de múltiplas possibilidades de se "ler Michel Pêcheux hoje"[4], com e para além de textos fundamentais velhos conhecidos nossos, como Semântica e Discurso[5], Discurso: estrutura ou acontecimento?[6] e Análise Automática do Discurso[7], além de outros textos já traduzidos e publicados em periódicos nacionais[8]. Dessa maneira, essa outra via instaura outras possibilidades tanto de retorno a Michel Pêcheux quanto de retorno do autor, o que abre para a produção de encontros e reencontros com o modo de ler o mundo proposto por Pêcheux a partir do discurso, expondo a produção da leitura à opacidade da linguagem, do sujeito e da história e ao trabalho simbólico da ideologia. Esse método de leitura é discutido ampla e densamente ao longo dos textos do volume.

A leitura desses textos, portanto, atualiza o movimento de elaboração teórica de Pêcheux, produzindo o retorno a - e (re)encontros com - conceitos e noções fundadoras da teoria do discurso: língua; simbólico; efeito e processo discursivo; memória; metáfora e metonímia; intra e interdiscurso; materialidade discursiva; formação discursiva; ideologia(s); discurso; condições de produção; a distinção entre lugar e posição, e entre documento e monumento; modos de produção e reprodução etc. Conceitos e noções que vão sendo (re)formulados na medida em que Pêcheux discute, ao longo dos textos, os fundamentos da teoria marxista que rompem com o empirismo, o logicismo, o sociologismo, o idealismo; a cientificidade das disciplinas de interpretação; o papel da Linguística relativamente a uma teoria não-subjetiva da subjetividade, logo, à Psicanálise e ao Marxismo; a distinção entre espaços discursivos logicamente estabilizados e espaços discursivos não estabilizados logicamente; a especificidade da Análise Automática do Discurso (AAD-69); a questão da luta de classes; a definição dos objetos discursivos tanto na escrita quanto na oralidade e em relação a outras formas de linguagem, etc. Todo esse trabalho visando à sustentação de uma posição e de um método materialista de leitura dos processos de significação em que o sentido é compreendido como efeito, a unidade como aparente, a descontinuidade, as desigualdades, os desnivelamentos como incontornáveis... a contradição como constitutiva.

A leitura do conjunto dos textos, como já sugeri, nos situa grande parte do tempo na década de 1970, período de forte investimento por parte de Pêcheux em relação à análise de discurso, e mais especificamente ao dispositivo da Análise Automática do Discurso (AAD69), para o qual o recurso à informática[9], para efeito de análise, era sistematicamente examinado, testado e implementado, como uma espécie de objeto de desejo que pudesse mais rápida e seguramente conduzir as pesquisas a alcançarem seu objetivo: estabelecer os domínios semânticos e as relações de dependência entre eles como modo de determinar o discurso inconsciente das ideologias. Acredito que isso explique, parcialmente, a razão pela qual as atividades de pesquisa levadas a termo por Pêcheux e seus colegas pesquisadores tenha privilegiado a análise de discursividades constituídas sobre bases linguísticas escritas e orais (embora Pêcheux aponte, mais de uma vez, que a teoria de discurso abrange discursividades constituídas sobre bases linguageiras diferentes da verbal).

A questão histórica da divisão do trabalho intelectual e do estatuto das práticas intelectuais (se científicas ou não, por exemplo) é uma temática que Pêcheux procura compreender em mais de um dos textos da coletânea. A situação das ciências sociais, da filosofia, da psicologia social é analisada no primeiro dos 18 textos da coletânea, em que Pêcheux assina Thomas Herbert, publicado em 1966: "Reflexões sobre a situação teórica das ciências sociais e, especialmente, da psicologia social". Ali, Pêcheux discute a questão tentando estabelecer o processo histórico que produzia a relação, no "palco da prática social" (p. 38), entre práticas políticas e técnicas e os produtos ideológicos que estariam em continuidade com essas práti- 
cas. Ao mostrar que o discurso é o instrumento de transformação da prática política, cuja função é, segundo ele, transformar as relações sociais reformulando a demanda/comanda social por meio de um discurso, ele compreende a ideologia como o poder que trabalha na prática política. É dessa maneira, na perspectiva de Pêcheux, que surgem as condições ideológicas necessárias para o aparecimento de práticas científicas, que se caracterizariam pelo trabalho teórico de transformação de uma generalidade conceitual ideológica inicial, do qual decorreria, via corte epistemológico, uma configuração científica tal capaz de rearticular conceitos. Esse trabalho teórico se distingue por sua vez do método[10], explica Pêcheux, o que acarreta uma divisão no conjunto das práticas científicas estabelecida sobre as diferentes funções desempenhadas pela teoria e pelo método no processo de produção científica: assim, o conjunto seria composto de ciências desenvolvidas - em que o objeto e o método são homogêneos, engendrando-se reciprocamente - e de aventuras teóricas (ciências em estado nascente) - em que o acesso ao objeto precisa ser construído, "obtido por caminhos ainda não trilhados, onde os passos em falso não estão excluídos" (p. 47). Finalmente, o que Pêcheux mostra é que, no estado em que se encontravam naquele momento, as ciências sociais - sobretudo a psicologia, a sociologia e a psicologia social - não produziam conhecimento científico; ao contrário, funcionavam como aplicação de práticas técnicas particulares a uma ideologia das relações sociais, produzindo, dessa maneira, "uma ideologia expressiva da prática social global" (p. 51) a partir da elaboração de uma resposta à demanda/comanda social visando a (re)adaptar as relações sociais à prática social global - operação designada por Pêcheux como uma "'realização' do real psico-sociológico" (p. 51).

"As ciências humanas e o momento atual" é outro texto em que a divisão do trabalho intelectual é tratada, com destaque desta vez para as dificuldades que as ciências sociais enfrentavam para produzir deslocamento em suas práticas teóricas, o que decorria, segundo Pêcheux, do esquecimento por parte dessas ciências do elemento político em favor do centramento sobre a política, "pelo qual as ciências humanas se pensam como o lugar da política" (p. 185). Nessa perspectiva, Pêcheux considerava que a teoria marxista poderia exercer um papel fundamental no processo de deslocamento da linha dominante - organicista-tecnicista que caracterizava as ciências sociais naquele momento, pois interviria efetivamente no processo de produção de conhecimento impondo, por um lado, obstáculos ao idealismo e à filosofia espontânea, e estabelecendo, por outro lado, através do materialismo histórico, um "núcleo científico de uma ciência das formações sociais e de sua transformação histórica" (p. 200).

Em "Nota sobre a questão da linguagem e do simbólico em psicologia", Pêcheux, juntamente com Gadet, Haroche e Henry, defende a irredutibilidade da linguagem a um mero substrato de caráter lógico, cognitivo, neurológico, inato ou adquirido, e a uma ordem homogênea, opondo-se fortemente aos trabalhos de Chomsky, de um lado, e de Piaget, de outro. Os autores assumem a noção de linguagem que permitiria colocar em perspectiva um trabalho materialista em relação à discursividade: assumem os vínculos entre inconsciente, língua e subjetividade, mostrando que o específico da linguagem é justamente sua ligação ao simbólico - compreendido, a partir de Lacan, em sua relação específica com o real e com o imaginário, "determinando a subjetividade como efeito da interpelação de que o sujeito é o lugar, pelo viés da identificação" (p. 64).

A propaganda - por reunir, de um lado, imagens, palavras, sentimentos, ideias e gestos, e, por outro lado, funcionar como dispositivo essencial do Estado autoritário moderno constitui o objeto de análise em "Foi 'propaganda' mesmo que você disse?": um lugar privilegiado, decisivo para se observar o processo de produção e o funcionamento de um "corpo 
teórico-político profundamente instalado nas evidências" (p. 79) da modernidade; uma das formas históricas de assujeitamento do indivíduo. Nesse texto, Pêcheux percorre as bases da história política da propaganda, focando o percurso de um "especialista da propaganda" russo, Serguei Tchakhotin, atuante nas longas primeiras décadas do século XX, como figura importante do alto escalão administrativo anti-tsarista, anti-fascista e anti-capitalista; um obstinado política e cientificamente, segundo Pêcheux, idealizador de uma biopsicologia da propaganda, cujos efeitos encontravam-se ainda ressoantes na época de produção de sua análise. O objetivo com esse texto era delinear as condições de exercício da propaganda política, mostrando, particularmente, as formas históricas de um princípio que, segundo Pêcheux, não parou de ecoar entre a burguesia e o proletariado e que se formula da seguinte maneira: "se isso funciona tão bem para eles, por que não funcionaria para nós?" (p. 82). Pêcheux mostra que a propaganda passa a constituir fortemente uma arte (=arma) a serviço do Estado, desenvolvendo estratégias discursivas obstinadas em "evacuar qualquer contradição e a mascarar a existência das relações de classe" (p. 86), um dispositivo eficaz no processo de fazer a política parecer uma atividade imaginária, colocando-a numa "ordem do parecer" em que gestos e declarações passam a substituir as práticas... Foi assim que o Estado capitalista, afirma Pêcheux, "passou a ser mestre na arte de agir à distância" (p. 91), anestesiando as resistências, absorvendo as revoltas no consenso e fazendo abortar as revoluções, trabalhando dessa maneira diferentes formas de manter o assujeitamento, para o qual, adverte Pêcheux, a ausência de escuta persiste politicamente.

Em uma entrevista, publicada com o título "A língua inatingível" (1983), Pêcheux e Gadet falam do trabalho de análise sobre a relação entre história, ideologia, língua e discurso lançado como livro com título homônimo em 1981[11]. Nessa entrevista, os autores retomam aspectos do percurso que se desdobra no livro, dando ênfase ao fato de que a análise de discurso considera o alcance das materialidades discursivas inerente aos processos ideológicos, o que implica pensar aí a relação desses processos com a linguagem. Nessa perspectiva, a análise de discurso se põe a ler a relação entre realidade histórica, materialidade linguística e a existência do sujeito, como alternativa à obsessão pela elaboração de uma teoria impossível de universais semântico-pragmáticos - que seria a forma mais recente, segundo Pêcheux, da língua inatingível, objeto de dominação e de desejo perseguido por certas práticas intelectuais como a Linguística. Gadet, nessa entrevista, retoma o capítulo do livro intitulado "A metáfora também merece que se lute por ela", para lembrar que, na perspectiva discursiva, não há desvio, o que permite considerar que não há linguagem poética: "há somente um processo geral de linguagem, funcionando tanto no aprendizado verbal de crianças quanto no uso cotidiano da linguagem por todos os falantes, bem como nos seus usos político e literário" (p. 104). Este seria um dos pontos de partida, desde o qual os autores afirmam no livro o valor político e histórico da falha constitutiva da língua, "contra o narcisismo da comunicação bem-sucedida" (p. 105), mostrando que o jogo na/da língua se dá pelas coerções, lacunas e latitudes que ela própria oferece - esta é, segundo ela, uma característica do sistema linguístico: "permite deslocamentos históricos dentro do campo das formulações possíveis" (p. 100).

"Efeitos discursivos ligados ao funcionamento das relativas em francês" é um texto em que Pêcheux também explicita sua posição contrária ao referido projeto de estabelecimento de uma semântica universal, que se pretende não-ambígua, funcionando como uma espécie de "língua 'ideal' suscetível de regular a produção e a interpretação dos enunciados" (p. 131). Para tanto, Pêcheux coloca em destaque a interpretação do funcionamento ambíguo das relativas em francês para mostrar que tal projeto é uma ilusão e se sustenta em um dispositivo interpretativo que procura eliminar a ambiguidade. Ambiguidade compreendida por Pêcheux, a partir das análises, como efeito discursivo: "ponto de contato entre o linguístico e o ideoló- 
gico" (p. 136). O discurso - relembra Pêcheux neste texto de 1981 - "representa no interior do funcionamento da língua os efeitos da luta ideológica e, inversamente, ele manifesta a existência da materialidade linguística no interior da ideologia" (p. 136). Acrescenta ele ainda que é a própria estrutura da língua que torna possível os processos discursivos cuja existência "pertence de maneira constitutiva e co-extensiva ao campo da luta ideológica e política das classes" (p. 137).

O questionamento acerca do estatuto e do funcionamento da ideologia também é uma temática recorrente nos textos de Pêcheux, como em "Ideologia - aprisionamento ou campo paradoxal?", em que o autor se propõe a analisar a "forma pela qual o 'socialismo existente' inscreve sua relação na história do desenvolvimento do capitalismo" (p. 107). Aí Pêcheux percorre a divisão histórica entre centro e periferia e as formas ideológicas de submissão do indivíduo, fazendo notar certas ambiguidades e paradoxos produzidos pelo discurso político. Adverte para a compreensão da noção de "reprodução" como diferente de "reprodução do mesmo" ( $c f$. p. 115), especialmente ao retomar Althusser, para reafirmar que os processos de reprodução ideológicos também funcionam como um lugar de resistência múltipla: "local no qual surge o imprevisível contínuo, porque cada ritual ideológico continuamente se depara com rejeições e atos falhos de todos os tipos, que interrompem a perpetuação das reproduções" (p. 115). Pêcheux mostra nesse texto que a singularidade das lutas de deslocamento ideológicas próprias ao processo que ele analisa, pois constituem os mais diversos movimentos populares, insiste na repreensão de objetos paradoxais - "povo", "direito", "trabalho", "gênero", "liberdade" etc. - que são "simultaneamente, idênticos consigo mesmos $e$ se comportam antagonicamente consigo mesmos" (p. 115). Dessa maneira, ele aponta para a necessidade de se assumir os riscos e refletir sobre "esses processos ideologicamente heterogêneos, contraditórios, assimétricos e deslocadores, considerando-os relacionados a transformações práticas, que aparecem perante nossos olhos nas formas sócio-históricas da subjetividade, nos métodos organizacionais das lutas, na percepção dos acontecimentos e nos registros da discursividade" (p. 118).

Com “Língua, 'linguagens', discurso", Pêcheux analisa o papel ambíguo desempenhado historicamente pela Linguística ao ser tomada como ciência-piloto relativamente às ciências sociais, à história e à literatura. Ele mostra que metaforicamente a linguística serve de “caução a um empreendimento 'de análise geral do inteligível humano', isto é, a uma impossível ciência da realidade [...] acima das outras ciências" (p. 127). Em relação a essa problemática, Pêcheux explicita o lugar de uma teoria do discurso no materialismo dialético, em que a língua é concebida como a base, o suporte, sobre o qual os processos - por conseguinte, as relações sociais - se constroem; e o processo de produção do discurso corresponderia ao "funcionamento da base linguística em relação a representações postas em jogo nas relações sociais" (p. 128). É nessa direção que o autor vislumbrava a possibilidade de desenvolvimento das relações entre a linguística e a teoria do discurso, no interior do materialismo histórico.

"Leitura e memória: projeto de pesquisa" é o texto de um projeto de pesquisa proposto por Pêcheux à Comissão de Psicologia do Centro Nacional de Pesquisa Científica (CNRS) em 1982, cujo objetivo era analisar a questão da memória e da leitura por um método alheio a qualquer prerrogativa neurobiológica ou cognitiva; ao contrário, Pêcheux propõe tratar a memória a partir de seu estatuto social o que lhe permite analisar seu funcionamento discursivo, em uma prática de leitura defina em torno das discursividades não estabilizadas logicamente. Ao discorrer sobre sua proposta, Pêcheux estabelece a relação entre leitura e memória (corpo/corpus sócio-histórico de traços discursivos) e destaca o papel dos efeitos do interdiscurso (corpo de traços que formam memória) na produção das análises intradiscursivas, isto é, para 
a compreensão de como esses efeitos intervêm na estruturação das sequências intradiscursivas.

"Metáfora e interdiscurso" é um dos textos póstumos que integram a coletânea de textos de Pêcheux cuja discussão é situada na análise dos processos discursivos que sustentaram práticas e saberes produzidos ao longo do século XIX. Pêcheux trata essa questão tomando como ponto de partida a produção discursiva do sentido de um enunciado - isso para colocar em xeque o consenso em torno da ampla cientificidade de certas noções semânticas e pragmáticas. Logo de saída, Pêcheux assevera a importância de levar a termo a noção de materialidade discursiva: "nível de existência sócio-histórica, que não é nem a língua, nem a literatura, nem mesmo as 'mentalidades' de uma época, mas [...] as condições verbais de existência de um objeto (científicos, estéticos, ideológicos...) em uma conjuntura histórica dada" (pp. 151152). Para Pêcheux, a questão primordial recai sobre as formas de existência histórica da discursividade, o que o faz lembrar-se da noção de formação discursiva introduzida por Foucault (Arqueologia do saber), deslocando-a ao relacioná-la com a noção de interdiscurso - como princípio de funcionamento da discursividade e cujos efeitos se desenvolvem em contradições - e com as noções de metáfora (perturbação que pode tomar a forma de lapso, ato falho etc.) e metonímia (tentativa de "tratar" esta perturbação, de reconstruir suas condições de aparecimento).

No texto escrito com Jacqueline Léon, "Análise sintática e paráfrase discursiva”, o tema principal é a posição teórico-metodológica da análise de discurso, que opera sobre situações em que, dada uma questão, não se pode contar com alguma resposta explícita que lhe seja preexistente. No texto, os autores percorrem as questões da leitura e do sentido de um texto, dos dados e do corpus, do enunciado, da sequência discursiva, do papel da sintaxe para o dispositivo de leitura, da constituição de arquivos. Afirmam que o processo discursivo somente se torna visível porque as sequência discursivas de um corpus/arquivo são postas em relação - pela via das ligações horizontais e das paráfrases: pontos em que a sintaxe opera numa ordem discursiva; pontos em que a identidade de sentido, afirmam os autores, é ameaçada pelos espelhamentos e pela deriva. É nessa medida que é possível deslocar a análise de texto em direção à produção discursiva do sentido, trabalhando a tensão contraditória constitutiva entre o mesmo e o diferente (o outro).

“A análise de conteúdo é uma técnica ou a aplicação de uma ciência?", "há uma aplicação de uma disciplina como a linguística?" são perguntas que Pêcheux problematiza no texto "A aplicação dos conceitos da linguística para a melhoria das técnicas de análise de conteúdo". Discussão que serve também para reafirmar o conceito de discurso como ponto de sustentação de análises sobre o que, "na linguagem, concerne às restrições que não são nem fonológicas, nem morfológicas, nem sintáticas, mas ligadas de um modo ou de outro aos efeitos de clivagem" (p. 214). Pêcheux explicita nesse texto um quadro conceitual relacionando as noções de discurso, condições de produção, produção de um efeito, lugar e posição, sujeito e análise linguística: um quadro de sustentação de um método que impõe como exigência a necessidade de fazer relacionar, em uma análise discursiva, o dito e o não-dito, sequências discursivas parafrásticas e textos análogos do ponto de vista das condições de produção que os dominam... Tudo isso com o objetivo de tornar visível "aquilo de que se trata no discurso [...] o objeto construído no discurso" (p. 222).

Em um texto mais rápido, em relação ao anterior, publicado postumamente (1984), Pêcheux sintetiza a "Especificidade de uma disciplina de interpretação", descrevendo o que ele denomina "posições de trabalho frente à discursividade" (p. 227). Os pontos que estabele- 
cem essa especificidade podem ser assim elencados: 1) a análise de discurso se caracteriza por sua relação com a língua e pela prática de construção de um corpus; 2) a análise de discurso se ocupa com apreender e descrever as condições estruturais de existência do sentido; 3) a análise de discurso considera as condições históricas de existência de discursos na sua heterogeneidade, reintroduzindo aí a questão da língua; 4) os limites da análise ultrapassam as fronteiras da frase, "trabalhando a heterogeneidade discursiva no jogo das contradições sóciohistóricas: analisa-se uma sequência na sua relação com seu exterior específico (em particular seus pré-construídos, seus discursos relatados etc.) e em relação à alteridade discursiva com que ela se defronta, ou seja, o campo sócio-histórico do qual ela se separa" (p. 229). Nessa perspectiva epistemológica, a língua é compreendida como "o real específico formando o espaço contraditório do desdobramento das discursividades" (p. 228); o interdiscurso é compreendido "como condição da produção e da interpretação dos discursos" (p. 229); e a questão crucial, afirma Pêcheux, para a análise de discurso, como uma disciplina de interpretação "é a do estatuto do sujeito enunciador, na fala e na escrita, na escuta e na leitura" (pp. 229-230).

A especificidade da análise de discurso assim estabelecida é apresentada também em outro texto póstumo que integra a coletânea, cuja versão brasileira já havia sido publicada na revista Escritos ( $\mathrm{n}^{\circ}$. 4, Labeurb/Nudecri/Unicamp, 1999): "Sobre os contextos epistemológicos da análise de discurso". Neste texto, vale relembrar, Pêcheux enfatiza os pontos de ruptura da análise de discurso em relação à posição de trabalho de caráter psicossocial, que recalcava o triplo registro caracterizado por relacionar constitutivamente história, língua e inconsciente. Descreve o método de análise como o procedimento que expõe "o olhar-leitor a níveis opacos à ação estratégica de um sujeito" (p. 291), um procedimento de leitura - insiste ele - "em que o sujeito é ao mesmo tempo despossuído e responsável pelo sentido que lê" (p. 291). Com efeito, Pêcheux define aí o campo da análise de discurso como aquele determinado pelos espaços discursivos não estabilizados logicamente ( $c f$. também p. 143) - constituídos em diferentes domínios, como o filosófico, o sócio-histórico, o político, o estético, os registros do cotidiano, etc.

"Há uma via para a linguística fora do logicismo e do sociologismo?" é outro texto também já publicado anteriormente na revista Escritos ( ${ }^{\circ}$. 3, Labeurb/Nudecri/Unicamp, 1998)[12], em que Pêcheux e Gadet procuram responder a pergunta-título, uma vez que o ponto de vista dos autores remete a uma posição de trabalho materialista sobre a língua, sobre os fenômenos da linguagem e sobre as práticas linguísticas. Para eles, essa posição não é realizável a partir das tendências logicista e sociologista que representam os dois polos contraditórios entre os quais a história da linguística se desenvolveu, pois ambas, mostram os autores, funcionam como formas idealistas de denegação da política (e do político) e de subjetivação da teoria da linguagem, sustentadas nas evidências do humanismo burguês clássico. Pêcheux e Gadet asseveram que a teoria do discurso que propõem e praticam - por meio das noções de discurso e formação discursiva - constitui uma via possível para desencadear o processo de desubjetivação da teoria da linguagem, pois permite pensar a relação constitutiva entre língua e formações ideológicas que funciona como suporte das práticas linguísticas. A língua, nessa perspectiva, funciona como "a base comum de processos discursivos diferenciados" (p. 309) e o processo discursivo se configura como "o sistema das relações de substituição, paráfrases, sinonímias etc. funcionando entre elementos linguísticos - 'significantes' - em uma formação discursiva dada" (p. 309).

No texto "Posição sindical e tomada de partido nas ciências humanas e sociais", Pêcheux analisa as condições da luta sindical e política em relação aos intelectuais universitários das ciências humanas e sociais, particularmente na França, tal como se configurava na época 
(Pêcheux se referirá a isso como a relação entre o aparelho de Estado, o aparelho político e o aparelho universitário ( $c f$. pp. 245 et seq.)). Pêcheux destaca como o poder (Estado/burguesia) "organiza a escassez para suscitar a inquietude e a docilidade das pessoas e desenvolver a concorrência entre as formações de modo que sobrevivam e desenvolvam-se mais aptas a... servir o capitalismo" (p. 236). Pêcheux mostra como se distribui a contradição que constitui a relação dos intelectuais universitários das ciências humanas e sociais com o Estado (o poder), mais especificamente em relação ao dispositivo (anti)democrático aí em jogo/disputa, e, ao mesmo tempo, com a política, sobretudo porque, explica Pêcheux, a ideologia dominante mantém-se funcionando sob formas variadas em qualquer cenário: entre conservadores, reacionários, reformistas ou esquerdistas. Essa contradição e seus efeitos indiciam a ausência, segundo Pêcheux, de uma posição marxista-leninista sobre as e nas ciências humanas e sociais, ou seja, "colocar-se do ponto de vista político da classe operária" (p. 242); uma posição que considera o "conhecimento (sempre incompleto, porque em desenvolvimento) da realidade histórica das formações sociais e de sua transformação, por conseguinte, o conhecimento (sempre incompleto, porque em desenvolvimento) das condições concretas de existência do 'homem e da sociedade', conhecimento indispensável à transformação dessas condições concretas" (pp. 242-243), uma posição, em suma, materialista, contra o idealismo ( $c f$. p. 248)[13].

“As massas populares são um objeto inanimado?" é mais uma das perguntas provocativas que intitula esse texto de Pêcheux (de 1978), que é uma versão reduzida de um trabalho mais amplo conduzido em parceria com Paul Henry, Jean-Pierre Poitou e Claudine Haroche, intitulado Un exemple d'ambiguité idéologique: le rapport Mansholt[14]. Nesse texto, Pêcheux investe em um fundamento vigoroso e produtivo para a análise de discurso: "a política tem, indiscutivelmente, efeitos na linguagem, e não são efeitos desconexos" (p. 252). Ele faz isso ao mostrar e defender uma tese, formulada da seguinte maneira: "o par semântico pessoa/coisa, que 'cola' sem problema aparente nos enunciados da vida cotidiana, não mais se aplica quando se trata de política no sentido não-burguês do termo, isto é, desde que se trate da política das massas" (p. 252). Com uma advertência: "falar das massas populares, de mudança política e de revolução, enfim, da história, em termos de pessoas e de coisas, de sujeitos e objetos, de intenções e do estado das coisas, como algo natural, como distinções transparentes que aparecem na linguagem sem qualquer ambiguidade, é desconsiderar totalmente a constituição essencialmente ideológica do discurso e do sentido" (p. 252). Para trabalhar a referida tese, Pêcheux e o grupo de pesquisadores com quem trabalhava na época fizeram uma experiência distribuindo para dois grupos de 25 jovens universitários um mesmo texto com notas que indicavam autorias diferentes: para o primeiro grupo o texto para leitura circulou como se escrito por um economista de esquerda; e para o segundo grupo como se escrito por um economista de direita[15]. Foi, em seguida, solicitado aos estudantes que fizessem um resumo do texto após sua leitura. As conclusões a que chegaram Pêcheux e seu grupo, após trabalharem esse material pelo procedimento da análise automática do discurso (AAD-69), desdobram-se da seguinte maneira: (1) a leitura objetiva de um texto não pode ser realizada uma vez que não há senso comum no que concerne a política; (ou seja) (2) palavras, expressões, enunciados significam diferentemente dependendo da posição da qual são formuladas; (1) e (2) minam qualquer fundamento em favor de uma semântica universal; (3) "no terreno da linguagem, a luta de classes ideológicas é uma luta pelo sentido das palavras, expressões e enunciados, uma luta vital por cada uma das duas classes sociais opostas que têm se confrontado ao longo da história" (p. 273); (4) a análise dos resumos dos estudantes, permite organizar o pensamento burguês oscilando continuamente entre duas concepções de sociedade: (a) a metáfora da sociedade compreendida como uma coisa ("um mecanismo, uma máquina que pode funcionar mal, e que deve ser monitorada, controlada e ocasionalmente reparada" (p. 272)) e (b) a 
metáfora da sociedade como um agente animado ("um projeto comum articulado por tomadas de decisões consensuais” (p. 273)).

Por último, em um texto de 1981, "Análise de discurso e informática", Pêcheux apresenta, em um primeiro momento, uma retrospectiva da Análise Automática do Discurso (AAD-69), que nasceu com um objetivo de analisar o " discurso inconsciente' das ideologias" (p. 277), apoiando-se estrategicamente, por um lado, no estruturalismo linguístico, levando-o "a sério" (sobretudo, a partir de Saussure e Harris), e, por outro lado, em uma plataforma (programa) informática que possibilitasse uma análise algorítmica de base e processamento computacionais, cuja função era a de operar comparações lexicais e agrupamentos semânticos permitindo o estabelecimento de "domínios semânticos" e relações de dependência entre eles. No segundo momento do texto, Pêcheux dá notícias de como se configuravam as pesquisas do grupo ADELA (Análise de Discurso e leituras de arquivo) naquele momento, em que a aplicação da informática permitiria sustentar a tese de que "as ambiguidades, metáforas e deslizamentos próprios às línguas naturais são propriedades incontornáveis do campo da análise de discurso" (p. 281) - acrescentando que "um corpus de arquivo textual não é um "banco de dados"” (p. 281), ao contrário, é caracterizado por sua heterogeneidade contraditória. Além disso, Pêcheux adverte que a informatização da análise não tem como objetivo constituir uma "prótese da leitura, máquina de lavar textos, ou aparelho de raio X” (p. 282).

Como procurei mostrar, as possibilidades de acesso à especificidade da teoria de discurso trabalhada e estabelecida por Michel Pêcheux na França, entre 1966 e 1983, são múltiplas e se singularizam no gesto de sua escrita/transmissão, que esses 18 textos, na relação com tantos outros que conhecemos, materializam... mais de uma vez. A prática de leitura de Michel Pêcheux, seus trabalhos de/em análise de discurso - para um analista ou não, acredito sempre deixa/produz lições.

Reli algumas vezes a formulação que selecionei como epígrafe a essa resenha... produziu efeitos diferentes em mim e a lembrança de outro mestre, Prof. Ernesto, que nos advertia, em mais de uma aula, eu me lembro, que a conjuntura atual tornava possível que na sala ao lado da nossa pudesse haver pessoas discutindo e defendendo exatamente o contrário do que discutíamos e defendíamos em nossos encontros. Isso me soa como uma advertência marxista-leninista!: "os marxistas-leninistas repetem frequentemente que nada no mundo se desenvolve sem contradição" (p. 249)... ou ainda "as contradições da luta de classes atravessam e organizam o discurso sem nunca serem claramente resolvidas". Às (re)leituras de Pêcheux!

[1] In: "Efeitos discursivos ligados ao funcionamento das relativas em francês", p. 134. Obs.: todas as páginas que serão citadas ao longo deste texto correspondem à edição da obra que resenha.

[2] O lapso constatado no sumário, tanto na primeira quanto na segunda edição, por exemplo, foi contornado: refiro-me à ausência de separação gráfica entre os textos "Língua, "linguagens', discurso" e "Efeitos discursivos ligados ao funcionamento das relativas em francês", traduzidos, respectivamente, por Freda Indursky e José Horta Nunes.

[3] $C f$. http://www.labeurb.unicamp.br/portal/pages/home/lerArtigo.lab?id=48\&cedu=1 
[4] Faço referência ao título do texto que abre e prefacia a coletânea de textos de Pêcheux, escrito pela Profa. Eni Orlandi.

[5] PÊCHEUX, M. Semântica e Discurso: uma crítica à afirmação do óbvio. Trad. Bras. de Eni P. Orlandi et al. Campinas: Ed. da Unicamp, 1988 [4 ed. de 2009]. Título original: Les vérités de la Palice (Paris, Maspero, 1975). Versão inglesa: Language, semantics and ideology: stating the obvious (Londres, Macmillan, 1982, com o anexo - escrito entre 1978-1979 - "The French political winter: beginning of a rectification").

[6] PÊCHEUX, M. O discurso: estrutura ou acontecimento. Trad. Bras. de Eni P. Orlandi. Campinas, SP: Pontes, 1990 [6 $6^{\mathrm{a}}$ ed. de 2012]. Título original: "Discourse: Structure or Event?" (1983) In: NELSON, C.; GROSSBERG, L. (Eds.). Marxism and the Interpretation of Culture. Urbana; Chicago: University of Illinois Press, 1988. pp. 633-650. Este texto corresponde à comunicação proferida em 1983 por Pêcheux, na Universidade de Illinois (EUA), no colóquio "Marxism and the Interpretation of Culture: limits, frontiers, boudaries", publicado em sua versão original em francês "Le discours: structure ou événement?" em MALDIDIER, D. L'inquiétude du discours. Paris: Éditions des Cendres, 1990. pp. 303-323.

[7] PÊCHEUX, M. (1969). Análise Automática do Discurso. In: GADET, F.; HAK, T. (Orgs.). Por uma análise automática do discurso: uma introdução à obra de Michel Pêcheux. Trad. Bras. de Eni Orlandi et al. Campinas, SP: Ed. da Unicamp, 1990 [4ª ed. de 2010]. Título original: Analyse automatique du discours (Paris, Dunod, 1969, 142 p.).

[8] Lembro, particularmente, o texto "Delimitações, inversões, deslocamentos" cuja versão brasileira (trad. de José Horta Nunes) foi publicada nos Cadernos de Estudos Linguísticos n. 19 (IEL/Unicamp, Campinas, 1990, pp. 7-24).

[9] Sobretudo por meio de algoritmos de tratamento do texto (corpora/arquivos) que operavam procedimentos de seleção, comparação, aproximação e cálculos de grau de dependência.

[10] Pêcheux opera aqui com o seguinte conceito de método: "conjunto organizado da prática teórica que produz seu objeto sendo normatizado por ele" ( $c f$. p. 47).

[11] PÊCHEUX, M. \& GADET, F. La langue introuvable. Paris: Maspéro, 1981. Versão brasileira: A língua inatingível: o discurso na história da linguística. Trad. de Bethania Mariani e Maria Elizabeth C. de Mello. Campinas, SP: Pontes, 2004.

[12] Os números 1-4 da série Escritos estão disponíveis para download no endereço: http://www.labeurb.unicamp.br/portal/pages/publicacoes/lerArtigo.lab?id=31

[13] Pêcheux aponta para a necessidade de se conduzir de forma simultânea a luta contra o desmantelamento e a dependência do setor público de pesquisa em ciências humanas e sociais e a luta ideológica de classe sobre e nas ciências humanas e sociais, na França à época. A situação descrita e contra a qual ele se posiciona no texto, relativamente à configuração das ciências humanas e sociais naquele momento na França, parece-me ter progredido e se alastrado numa direção contrária à proposta por meio do apelo a tal "engajamento", para muito além dos limites franceses.

[14] In: Technologies, Idéologies, Pratiques, vol. 1, no. 2, avril-juin 1979, pp. 1-83. 
[15] Tratava-se de um texto de uma página extraído de um relatório elaborado pelo socialista Sicco Mansholt, em 1972, a respeito da "teoria do crescimento zero", que circulou com notoriedade na Comunidade Europeia nos anos 1970, segundo Pêcheux, pois apontava uma solução geral para a crise capitalista. 